\title{
GOVERNANCE AND ADAPTATION TO INNOVATIVE MODES OF HIGHER EDUCATION PROVISION
}

\author{
Silvia, FLOREA ${ }^{1}$ and Cecile, HOAREAU MCGRATH ${ }^{2}$ \\ "',Lucian Blaga" University of Sibiu, Romania, silvia.florea@ulbsibiu.ro \\ ${ }^{2}$ University of Maastricht, The Netherlands, cecile.hoareau@empowereu.org \\ On behalf of the GAIHE consortium
}

\begin{abstract}
In the context of the ever growing use of technology through e-learning and open-courseware, our paper describes a project that is being carried out by a consortium of twelve university partners and is coordinated by the University of Maastricht and RAND Europe (Cambridge). This project sets out to examine the evolution and sustainability of the innovative modes of higher education provision in teaching and learning across Europe, the motivations for their emergence as well as the ways in which higher education management and governance have responded and adapted to such new modes of provision. In the highly competitive sector of higher education (HE), while attempting to enhance the quality of teaching and learning, the increasing range of teaching and learning providers (encouraging both new delivery models and the 'unbundling of delivery' through partnerships, spin-out organisations, franchising, etc.), has challenged the 'traditional' model of university and stimulated changes in the provision and management of higher education.

Our paper describes the general framework of the project, foregrounding the first preliminary results of the first European-wide analysis of such innovative modes of provision in teaching and learning in Europe.
\end{abstract}

KEYWORDS: technology, higher education, MOOCS, governance.

\section{ACKNOWLEDGMENT}

The Project (Reference number: 539628-LLP-1-2013-1-NLERASMUS-EIGF) is entitled: Governance and Adaptation to Innovative Modes of Higher Education Provision (GAIHE), it is funded by the Education, Audiovisual and Culture Executive Agency (EACEA) through the Lifelong Learning Programme and it is run by a consortium of 11 partner Universities: Ecole Normale Supérieure de Lyon (France), University of Strasbourg (France), "Lucian Blaga" University of Sibiu (Romania), the Higher Education Policy Research Unit of Dublin Institute of Technology (Ireland), Academic Unit of the University of Latvia, Comenius University and the University of Ss. Cyril and Methodius (Slovak Republic) the University of Maribor (Slovenia), the University of Salamanca and the University of Alicante (Spain) and RAND Europe (Cambridge). The consortium partners are coordinated by the School of Governance (SoG) of the University of Maastricht, Netherlands. Project Duration is 36 months (01.10. 2013 to 31.03 .2016$)$.

\section{PROJECT BACKGROUND}

Our project aims to study governance and management changes of higher education institutions that have become increasingly fragmented ('unbundled') as a result of new technology and globalisation. It sets out to identify these innovations, analyse the motivations, drivers, barriers and impact of these innovations on the management and governance of higher education, as well as investigate the role of the university governance and management in innovative provision.

In its assessment and for clear project purposes and reference, the project reviews significances of such terms as: innovation, governance, management and unbundling and places them in the current HE European space.

Hence, an innovation is taken to mean the implementation of a new or significantly improved product (good or service), a process, a new marketing method, or a new organisational method in business practices, workplace organisation or external relations, according to UNESCO [1]. In addition, this project assumes that innovations have an increased added value, for example in terms of how learning takes place and how it is organised.

A broad debate already admittedly exists around identifying educational innovations and their origins, however for the purpose of this project, educational innovation is considered a trend that has expanded over the past five years and has attracted considerable attention, having the potential to provide fundamental alterations to the higher education offer. The governance of universities is responsible for overseeing its activities, determining its direction and monitoring the process whereas the management of universities is in charge of its operational running. In what regards unbundling, it represents "the process of breaking down a recently stable product unit size into component parts, forcing margin reduction and lower prices for consumers" [2] and, in higher education, various educational innovations are modifying this traditional model, making it possible to segment the educational offer by providing separate alternatives online offers.

Indeed, online offers have revolutionised the ability to unbundle the traditional educational offer, which typically merges content, learning \& teaching, assessment \& credentialing, research \& development, and business management [3]. Massive Online Open Courses (MOOCs) 
constitute an example of this trend toward the unbundling of content delivery [4]. With the rising new generation of tablettoting, hyper-connected youth, the university will continue to extend its reach to students around the world, unbounded by geography and time zones, at a fast pace and at a fraction of the cost of a traditional college education. "MOOCs are best viewed as higher education's version of TV networks offering individual shows (i.e., parts of the bundle) online for free" [5]; they provide access to recorded lectures, online tests and digital documents as alternatives to traditional classroom instructions. Instead of attending a face-to-face course, students may attend one course online, typically free of charge. Various MOOC initiatives, including Coursera or the Kahn academy, have been very much talked about in the US and beyond. Although the number of MOOCs has tripled since March 2013 [6], there are still twice fewer MOOCs than non-European MOOCs. But 'unbundling' of higher education includes not only MOOCs but franchising as well. Apple's online university, Wikipedia, or YouTube also provide additional learning channels. In addition, franchising represents the right to 'brand' products (deliver assessment and credits) so long as the franchisee adheres to strict standards and policies. As a result, branch campuses have multiplied [7] and have occurred wherever such extensions were possible, albeit such new developments are not being adopted uniformly, nor, one might add, without controversy [8]. Just to quote an example, the UK had 400 franchise arrangements in 2008. Likewise, currently there are seventy eight branch campuses registered worldwide, including thirty seven in the UAE, 18 in Singapore, 10 in Qatar, seven in Malaysia, two in Botswana and four in Hong Kong [9].

\section{RESEARCH QUESTIONS}

Such 'unbundling of delivery', through partnerships, spin-out organisations, franchising and the fragmentation of knowledge and information provision [10] as well as the growing range of providers, encouraging new delivery models (for example providing IT or e-based services) are apt to pose many and significant managerial challenges. In this context, 'traditional' higher education institutions have to rethink their governance models in order to adapt to these changes and domestic reforms.

Being able to understand how higher education adapt to these changes is important because modern history contains many examples of industries that failed to see the signs of major disruption early enough to avoid painful consequences to their businesses [11].

'Traditional' higher education provision typically includes a concentration of activities in the institution, a reliance on public grants and state control through a priori command and control rather than a posteriori evaluation, which does not necessarily match the new forms of management described above, based, for example, on unbundling and fragmentation. New managerial types are emerging, including the 'Amazon university', (based on e-learning and sharing content), the ondemand university, where students tailor their courses and credits over a period of time, the learning hotel, which continually changes flows of collaboration and interchanges between academic scholars and corporate, government or professional practitioners, as well as the umbrella university, which sees the university as a cooperative rather than a selfcontained entity with fragmented activities, the university becoming a 'holding structure with a conglomerate of separately managed businesses'[12]. Further models include the 'Corporate University' [13], arguably said to represent a "paradigm shift in the development of organisational human capital" [14] which is strategically oriented toward integrating the development of people as individuals with their performance as teams and ultimately as an entire organisation.

Against this background of changes in the landscape of higher education provision that have challenged the 'traditional' model of university and its future, our project aims to provide answers to several emerging key questions:

How do higher education institutions innovate their modes of provision, while respecting the quality of higher education?

How is the higher education management adapting to these new modes of provision?

Do higher education institutions innovate through a distributed leadership, which facilitates the adoption of bottom-up initiatives [15] or given a strong core, with a clear top-down innovation strategy [16]?

The project is based on a comparative analysis resulting in a final report including policy recommendations, survey results and case study reports. It informs and supports the exchange of best practices among the higher education management, national ministries and the international higher community regarding innovative modes of higher education provision. The desk research involves ENS and DIT. The survey involves DIT, Maribor and Comenius University. The case study analysis is led by the University of Latvia, also involving the University of St Cyrill, University of Alicante, University of Salamanca and ENS Lyon. The report elaboration is shared between the University of Maastricht, the University of Latvia and Comenius University of Bratislava.

\section{PRELIMINARY RESEARCH RESULTS}

This project draws on an online survey circulated around forty four higher education institutions, and some case study analyses. So far, the literature review (LR) has been completed which focused mainly on:

1. Description and analysis of innovations related to the modes of higher education provision as well as the governance and management of higher education institutions in a global framework.

2. Identification of the drivers and outcomes of innovation in higher education in Europe.

3. Making new connections between existing research on the challenges facing higher education and possible solutions offered by innovative modes of provision and innovative institutional governance or management implemented elsewhere.

Furthermore, the LR reviewed classification, benefits, and disadvantages of distributed leadership as well as leadership types resulting from a failed implementation of distributive leadership. The main outcomes were built on the works of Bolden et al (2009), Bennett et al (2003), Simkins (2005), Creanor (2011), and Jones et al (2012).

The LR discussed also how selected actors like: a) university staff (both academics and administrative staff), b) students and even the c) institutions themselves can potentially either facilitate or impede the introduction of innovation in higher education. 
As change agents, certain trends may impact students' expectations of higher education and attitudes toward learning. The current cohort of students is variously described as "digital natives", "new millennium learners" or the "net generation". They are characterized by non-linear thinking, multitasking, and interactivity, and their heavy reliance on technology and more specifically the internet that are also likely to push for structural and organizational innovations. The teaching staff plays perhaps the most active role in independently implementing innovation from the bottom up. Academic entrepreneurs could be viewed as those higher education actors who innovatively leverage internal and external opportunities to not only generate economic resources for their own profit or in support of their academic units and institutions, but also to create within the academy social and political change platforms. Despite of the fact, that academic institutions are many times described as possessing a culture of resistance to change, one of the key changes that can be made in order that institutions might benefit from both approaches and engender adaptive but sustainable innovation is by introducing flexible approaches that contribute to "an institutional culture of creativity and openness" (Brennan et al, 2014). In essence, this entails combining elements of negative and positive liberty; i.e. on the one hand adopting a position of non-interference and removing barriers where they exist, and, on the other, providing the appropriate support and resources where required.

As change barriers, it has been found that many students are uncomfortable with unfamiliar techniques and scenarios. Certain departures from traditional pedagogical methods can leave students, at least in the short term, disoriented. As for the academic staff, ongoing refinement of adaptive technologies that can provide tailored feedback, and the rise of team-based learning and peer-review style assessment, as well as the diminishing role of the academic as the 'gatekeeper' of knowledge can appear to undermine the skills of the teacher. With regards to more structural changes related to the introduction of the entrepreneurial university model, Jacob et al. (2003) identified the deficiency of entrepreneurial champions and leaders amongst the staff as the staff related barriers to the entrepreneurial turn, and the reasons for the absence of an entrepreneurial culture within the university. As for the organizational obstacles, apart from institutional resistance to innovations in the area of education provision, there is also evidence in the literature that institutions can act as barriers to the implementation of different structural and governance modes in higher education institutions.

Besides the analyses and their basic results described above, the LR raised several questions and tested the validity of the hypotheses related to the linkages between the various innovations introduced by higher education institutions. In doing this the focus was on correlations between innovative modes of higher education provision and changes in institutional governance and management. The posed questions were: 1. Do universities with a centralised leadership and a traditional core have more traditional educational provisions de facto? And conversely, Do institutions with a decentralised leadership automatically have an entrepreneurial strategy with innovative modes of education provision? How relevant are organisational structures in comparison to teaching professionals in the adoption of innovations? What is the sequencing of change events? Do changes in the organisational structure of institutions arise before educational innovation or can the latter create broader changes? Finally, what are the benefits of these educational innovations, if at all?

In conclusion, the LR highlighted that the higher education institutions are nowadays facing numerous challenges resulting from various global shifts and trends. The factors driving innovation were identified under five headings: the knowledge-economy, accessibility (or the appearance of mass education), financial pressures (due to primarily declines in public funding), the changing role of universities (i.e. increased pressures for universities to enhance development and boost innovation on a regional and national level) and disruptive innovation. Furthermore, universities are also increasingly pressured to adopt a third role (alongside teaching and research) and act as agents of innovation and development on both the regional and national levels.

Those drivers of innovation have led universities, among others, to introduce more innovative modes of provision (e.g. online learning and the use of different social media) as well as to challenge their traditional structures and innovate in the areas of higher education governance and management (which have been conceptualized in literature by the theories of Entrepreneurial University or Distributed Leadership). Further, the LR found it useful to distinguish these drivers of innovation from what are here referred to as agents of change - students, teaching staff, and higher education institutes. Interestingly, these agents of change also emerge in the literature as barriers to innovation, demonstrating the wide variation in attitudes to, motivations for and results of higher education innovation.

In the LR it was assumed that the higher education institutions have responded to those challenges by introducing various innovations in their systems and structures. Those have led to the introduction of more innovative modes of provision which include, among others, online learning and the use of different social media. Furthermore, universities have also challenged their traditional structures and introduced various innovations in the areas of higher education governance and management. Many of the changes introduced by universities have been conceptualized in literature by the theories of Entrepreneurial University or Distributed Leadership, with the former evolving around the ideas of tightening relationships with the private sector, promoting universities as innovation hubs, emphasizing the developmental role of universities and many more while the latter (which in fact is to an extent embodied within the former) underlines the need for diffusion of responsibilities and control within the institutions. It is also worthwhile mentioning that success or failure of the implementation of innovations in higher education is largely dependent on the individuals and institutions related to it.

The changes in modes of provision as well as institutional management and governance can potentially be correlated and impact one another. However, an analysis of the relationship of the aspects is very challenging due to rather limited empirical data available on the matter. To illustrate, although there appears to be a wealth of literature on innovative modes of higher education provision, much of it consists of descriptions of and extrapolations from smallscale case-studies; surveys on the implementation of very specific innovations; or policy recommendations prescribed as largely untested remedies to identified ailments. The 
selection of empirical research on technological and pedagogical innovations reviewed also broadly suggested ways in which institutional governance could provide support, but these again remain in the realm of recommendation rather than data on adaptations already implemented. The apparent sluggishness of institutions to respond to innovation is perhaps due to the fact that those surveyed, although diverse, can generally be characterised by their student-centred, distributed, flexible approach to education provision, which has been found to be difficult to cater for in the context of higher education institutions' typical hierarchical and bureaucratic structures. Thus, a thorough empirical investigation into the consequences of the innovations is needed to draw more concrete conclusions regarding their impacts on each other and on the higher education landscape as a whole. Such an empirical analysis is being conducted in the GAIHE project within the survey and case studies.

\section{CONCLUSIONS}

The research project proposes the first European-wide analysis of these innovative modes of provision in Europe, and will in turn, it is hoped, lead to opportunities for enhanced quality teaching and learning. The governance of higher education institutions is key to the diffusion of innovative practices for teaching and learning [17]. The research will fill a gap in our current knowledge and understanding by investigating the evolution of new modes of provision in teaching and learning across Europe, the motivations for the emergence of these new modes as well as how higher education management and governance have adapted to these new modes of provision. Its added value is represented by its significant contribution to decision-makers, higher education institutional managers, educators and importantly learners, providing them with an up-to-date assessment on new modes of provision and relevant policy recommendations. Nonetheless, the project is intended to be more than just a mere evaluative exercise. It has a strong informative component as an added value, hence, it is also a mapping exercise, including the implementation of MOOCs and OERs available to students throughout Europe. It will be also a useful education tool, practical to use, sustainable and effective, in the form of a toolbox for its users and contributes to providing an argumentation for policy-makers to support innovation.

\section{REFERENCES}

1. UNESCO Oslo Manual - Guidelines for collecting and interpreting innovation data, p. 46, Paris: 2005, UNESCO

URL:

http://www.oecdilibrary.org/docserver/download/9205111e.pdf?expires $=1384342823 \& \mathrm{id}=\mathrm{id} \&$ accname $=0$ cid $56013842 \&$ checksum $=$ E1E7DA3 E2312AB5F66F892C5734C9B0A

2. Ferreira, J., "The Unbundling of Higher Education", in Knewton Blog, 26 February, 2014. Available: http://www.knewton.com/blog/ceo-jose-ferreira/unbundling-highereducation/
3. Sheets, R.G., Crawford, S., (2012), "Harnessing the Power of Information Technology: Open Business Models in Higher Education", EDUCAUSE Review 47, no. 2, March/April 2012, accessed 17 July 2012, $<$ http://www.educause.edu/ero/article/harnessing-powerinformation-technology-open-business-models-highereducation $>$.

4. Fowler, G. 'An Early report card on MOOCs', in Wall Street Journal, R; and Wall street journal, 'The Opportunities and risks in the MOOC business model', $15^{\text {th }}$ of October 2013.

5. University Ventures 'The Great unbundling - popping bundles, not bubbles', UV Letter - Volume II, \#17, 2012, Available:

http://universityventuresfund.com/publications.php?title=the-greatunbundling

6. Open Education Europa, EC. Available: http://www.openeducationeuropa.eu/en/european_scoreboard_moocs

7. Altbach, P. 'Franchising: the McDonaldisation of higher education', in International Higher Education, 66 Winter, 2012. Available: https://htmldbprod.bc.edu/prd/f?p=2290:4:0::NO:RP,4:P0_CONTENT ID:116549

8. Wilkins, S. and Huisman, J., 'The International branch campus as transnational strategy in higher education', in Higher Education, 64:628, 2012.

9. Ibid.

10. Universities UK, Futures for higher education: analyzing trends, London: U.K, 2012.

11. Squires, L., Husmann, E., (2012), "Closing the gap between perception and reality for Open Education", European Foundation for Management Development (EFMD), EFMD Global Focus, January 2012.

12. P.A. Consulting group Escaping the red queen effect, Escaping the Red Queen Effect; Re-thinking the University in the New Economics of HE, London: P.A. Consulting Group, 2008.

13. Prince, C. and Beaver, G. 'The Rise and rise of corporate university: the emerging corporate learning agenda', in The International Journal of Management, 1(3),17-26.

14. Holland, P. and Pyman, A. "Corporate Universities: A Catalyst for Strategic Human Resource Development' in Department of Management Working Papers Series, Working Paper 39/05, May 2005.

15. Jones, S., Lefoe, G., Harvey, M., \& Ryland, K. (2012). Distributed Leadership: A Collaborative Framework for Academics, Executives and Professionals in Higher Education. Journal of Higher Education Policy and Management, 34(1), 67-78.

16. Clark, Burton (1998) Creating Entrepreneurial Universities: organizational pathways of transformation, Bingley: Emerald Group [17] Smith, K. 'Lessons learnt from the literature on the diffusion of innovative learning and teaching practices in higher education', in Innovation in higher education and teaching international, 49(2): 173-82, 2012. 